Article

\title{
The Effect of Fractional Time Derivative of Bioheat Model in Skin Tissue Induced to Laser Irradiation
}

\author{
Aatef Hobiny ${ }^{1}\left(\mathbb{D}\right.$, Faris Alzahrani ${ }^{1}$, Ibrahim Abbas ${ }^{1,2, *}$ and Marin Marin ${ }^{3}(\mathbb{D}$ \\ 1 Nonlinear Analysis and Applied Mathematics Research Group (NAAM), Mathematics Department, \\ King Abdulaziz University, Jeddah 21521, Saudi Arabia; ahobany@kau.edu.sa (A.H.); \\ falzahrani1@kau.edu.sa (F.A.) \\ 2 Mathematics Department, Faculty of Science, Sohag University, Sohag 82524, Egypt \\ 3 Department of Mathematics and Computer Science, Transilvania University of Brasov, \\ 500093 Brasov, Romania; m.marin@unitbv.ro \\ * Correspondence: ibrabbas7@science.sohag.edu.eg
}

Received: 6 March 2020; Accepted: 18 March 2020; Published: 10 April 2020

\begin{abstract}
This work uses the "fractional order bio-heat model" (Fob) model of heat conduction to offer a new interpretation to study the thermal damages in a skin tissue caused by laser irradiation. The influences of fractional order and the thermal relaxation time parameters on the temperature of skin tissue and the resulting thermal damage are studied. In the Laplace domain, the analytical solutions of temperature are obtained. Using the equation of Arrhenius, the resulting thermal injury to the tissues is assessed by the denatured protein ranges. The numerical results of the thermal damages and temperature are presented graphically. A parametric analysis is dedicated to the identifications of suitable procedures for the selection of significant design variables to achieve an effective thermal in the therapy of hyperthermia.
\end{abstract}

Keywords: fractional derivative; skin tissues; thermal damages; Laplace transforms

\section{Introduction}

Recently, the development of studies shows that the problem of heat transfer in living tissues introduces many complications. However, there are various discussions and findings in this field. Approaches of heating operations have been used in modernistic medicine, such as hyperthermia [1], laser tissue soldering [2], and laser surgery [3]. Some applications of bioheat models in clinical hyperthermia were discussed, especially regarding large, thermally unequilibrated blood vessels that have a worthy impact on the temperature distribution and cause serious temperature inhomogeneities. Through this clinical procedure, the applications of moving heat source on the skin tissue considering the perfusions rate is seen in some plastic surgery processes, such as in the use of laser radiation for spots or tattoos or in the heat actions of the cornea, using the laser for correcting hyperopia and removing moles.

In 1948, Pennes [4] presented the temperature distribution in the forearm skin temperature. The formulation can be analyzed by various approaches to get the solution of the heat transfer model for infinite thermal wave propagations, which is based on classical Fourier thermal conductions. In point of fact, it is still found that heat spreads at a finite rate in the biological tissue because they have highly nonhomogeneous inner structures. To dissolve the paradox that occurred in Penne's bio-heat formulation, thermal wave theory of bio-heat transfer is presented, which is based on heat waves constitutive relations, as given in [5,6]. Abbas and Hobiny [7] investigated the analysis of thermal damage in skin tissue subject to moving heat sources. The homotopy perturbation method [8] and the finite-decomposition method have also been applied [9]. Esneault and Dillenseger [10] investigated 
the temperature increment over times in hypothermia by the finite difference approach. Zhu et al. [11] estimated the depositions of light energy in tissues and the rate operation model for the thermal damage resulting from the use of the theorem of diffusions.

Many current models of physical processes have been successfully modified using fractional computation. We can say that the totality of integral theories and fractional derivatives was created in the last half of the last century. Definitions and different methods of fractional derivatives have become the main focus of numerous investigations. Using the fractional time derivative, many physical models' processes have been successfully modified. Ezzat et al. [12,13] introduced a new fractional bio-heat model using the fractional heat conduction equation. Ghanmi and Abbas [14] studied the fractional transient heating within the skin tissue owing to a moving heat source. Mondal et al. [15] investigated the transient heating within skin tissue owing to time-dependent thermal therapy in the context of memory-dependent heat transport law.

The analytical solutions are very interesting owing to their lower expense and accurate estimation compared with experimental and numerical calculations. Using the finite element approach, Diaz et al. [16] introduced the solutions of thermo-diffusions model in the tissue to study the resulting thermal damage. When a real phenomenon regarding heat transfer in a bounded media is studied, the nonlinear models and linear models of thermal transfer were developed and their numerical or analytical solutions are presented. Abbas and Zenkour [17] used the Green-Naghdi model to study the effect of rotation and initial stress on thermal shock problem for a fiber-reinforced anisotropic half-space. Abbas et al. [18] studied the effect of thermal dispersion on free convection in a fluid-saturated porous medium. Abbas [19] investigated the effects of relaxation times and a moving heat source on a two-temperature generalized thermoelastic thin slim strip. El-Naggar et al. [20] studied the effects of the initial stress, magnetic field, voids, and rotation on plane waves in generalized thermoelasticity. Marin and Marin et al. [21-23] used various models to study the dipolar bodies. Abbas [24] studied the nonlinear transient thermal stress analysis of a thick-walled FGM cylinder with temperature-dependent material properties. Zenkour and Abbas [25] used the finite element method to study the magneto-thermoelastic response of an infinite functionally graded cylinder.

This paper explores the effect of fractional order derivative on the thermal damage of living tissue using a bioheat model. The numerical results can be used as a substantiations division for living tissue interaction such as continual scanning laser interaction. The comparisons are made with the calculations obtained in the cases of the absence of the fractional time derivative and the thermal relaxation time parameters.

\section{Mathematical Model}

A semi-infinite biological tissue under thermal isolation is considered. On the basis of Cattaneo [5] and Ezzat et al. [12], the fractional bio-heat formulation in skin tissue can be expressed by

$$
k \nabla^{2} T=\left(1+\frac{\tau_{o}^{\alpha}}{\Gamma(\alpha+1)} \frac{\partial^{\alpha}}{\partial t^{\alpha}}\right)\left(\rho c \frac{\partial T}{\partial t}+\omega_{b} \rho_{b} c_{b}\left(T-T_{b}\right)-Q_{m}-Q_{e x t}\right), 0<\alpha \leq 1,
$$

Taking into consideration the above definition, it is possible to write the following:

$$
\begin{gathered}
\frac{\partial^{\alpha} h(\boldsymbol{r}, t)}{\partial t^{\alpha}}= \begin{cases}h(\boldsymbol{r}, t)-h(\boldsymbol{r}, 0), & \alpha \rightarrow 0, \\
I^{\alpha-1} \frac{\partial h(\boldsymbol{r}, t)}{\partial t}, & 0<\alpha<1, \\
\frac{\partial h(\boldsymbol{r}, t)}{\partial t}, & \alpha=1,\end{cases} \\
I^{v} h(\boldsymbol{r}, t)=\int_{0}^{t} \frac{(t-s)^{v}}{\Gamma(v)} h(\boldsymbol{r}, s) d s, v>0,
\end{gathered}
$$


The full spectrum of the local thermal condition can be described through the standard thermal condition using the definition of the fractional derivative given in Equation (2). The different values of fractional parameter $0<\alpha \leq 1$ cover two types of conductivity: $0<\alpha<1$ for low conductivity and $\alpha=1$ for normal conductivity. Here, $k$ is the thermal conductivity of tissue, $\omega_{b}$ is the rate of blood perfusion, $t$ is the time, $\rho_{b}$ is the blood mass density, $\rho$ is the tissue mass density, $T_{b}$ is the blood temperature, $T$ is the tissue temperature, $\tau_{o}$ is the thermal relaxation time, $c$ is the specific heat of tissues, $c_{b}$ is the specific heat of blood, $Q_{m}$ is the metabolic heat generations in living tissue, and $Q_{e x t}$ refers to the heat generated per unit volume of tissues. Gardner et al. [26] suggested the laser thermal source form by the following:

$$
Q_{e x t}(x, t)=I_{o} \mu_{a}\left[U(t)-U\left(t-\tau_{p}\right)\right]\left[C_{1} e^{-\frac{k_{1}}{\delta} x}-C_{2} e^{-\frac{k_{2}}{\delta} x}\right],
$$

where $U(t)$ is the unit step function, $\mu_{a}$ is the coefficient of absorption, $I_{o}$ is the intensity of the laser, $\tau_{p}$ is the exposure time of the laser, and $\delta$ is the penetration depth. $C_{1}, C_{2}, k_{1}$, and $k_{2}$ are the functions of diffuse reflectance $R_{d}$ and are mentioned in [26]. The penetration depth is defined by the following [26]:

$$
\delta=\frac{1}{\sqrt{3 \mu_{a}\left(\mu_{a}+\mu_{s}(1-g)\right)}}
$$

where $\mu_{s}$ is the scattering coefficient and $g$ is the factor of anisotropy. Now, both the lower and upper surfaces are supposed to be thermally isolated as the boundary conditions and the reference temperature are equal to its normal temperature. So, the initial conditions and the boundary conditions are presented as

$$
\begin{gathered}
-k \frac{\partial T(L, t)}{\partial x}=0,-k \frac{\partial T(0, t)}{\partial x}=0 \\
T(x, 0)=T_{b}, \frac{\partial T(x, 0)}{\partial t}=0.0
\end{gathered}
$$

For appropriateness, the non-dimensional forms can be given by

$$
\begin{gathered}
T^{\prime}=\frac{T-T_{o}}{T_{o}}, T_{b}^{\prime}=\frac{T_{b}-T_{o}}{T_{o}}, t^{\prime}=\frac{k}{\rho c L^{2}} t, \tau_{o}^{\prime}=\frac{k}{\rho c L^{2}} \tau_{o}, \tau_{p}^{\prime}=\frac{k}{\rho c L^{2}} \tau_{p}, x^{\prime}=\frac{x}{L}, \\
k_{1}^{\prime}=\frac{L}{\delta} k_{1}, k_{2}^{\prime}=\frac{L}{\delta} k_{2}, R_{b}=\frac{\rho_{b} \omega_{b o} c_{b} L^{2}}{k}, R_{m}=\frac{L^{2} Q_{m}}{k T_{o}}, R_{r}=\frac{L^{2} I_{o} \mu_{a}}{k T_{o}} .
\end{gathered}
$$

In terms of these non-dimensional form of physical quantities in (9), the governing Equation (1) initial and boundary conditions can be expressed as (for appropriateness, the dashes have been ignored)

$$
\begin{gathered}
\frac{\partial^{2} T}{\partial x^{2}}=\left(1+\frac{\tau_{o}^{\alpha}}{\Gamma(\alpha+1)} \frac{\partial^{\alpha}}{\partial t^{\alpha}}\right)\left(\frac{\partial T}{\partial t}-R_{b}\left(T_{b}-T\right)-R_{m}-R_{r} f(x, t)\right) \\
\frac{\partial T(0, t)}{\partial x}=0, \frac{\partial T(L, t)}{\partial x}=0 \\
T(x, 0)=0, \frac{\partial T(x, 0)}{\partial t}=0
\end{gathered}
$$

where $f(x, t)=\left[U(t)-U\left(t-\tau_{p}\right)\right]\left[C_{1} e^{-k_{1} x}-C_{2} e^{-k_{2} x}\right]$.

The transforms of Laplace for any function $M(x, t)$ can be expressed by

$$
\bar{M}(x, s)=L[M(x, t)]=\int_{0}^{\infty} M(x, t) e^{-s t} d t, s>0,
$$

where $s$ is the parameter of Laplace transform. Thus, the governing equations are expressed as 


$$
\begin{gathered}
\frac{d^{2} \bar{T}}{d x^{2}}-f_{1} \bar{T}=-f_{2}-f_{3} e^{-k_{1} x}-f_{4} e^{-k_{2} x} \\
\frac{\partial \bar{T}(0, t)}{\partial x}=0, \frac{\partial \bar{T}(L, t)}{\partial x}=0
\end{gathered}
$$

where

$$
\left(\begin{array}{c}
f_{1}=\left(1+\frac{s^{\alpha} \tau_{o}^{\alpha}}{\Gamma(\alpha+1)}\right)\left(s+R_{b}\right) \\
f_{2}=\frac{1}{s}\left(R_{b} T_{b}+R_{m}\right) \\
f_{3}=\frac{R_{r} C_{1}}{s}\left(1-e^{-s \tau_{p}}\right) \\
f_{4}=-\frac{R_{r} C_{2}}{s}\left(1-e^{-s \tau_{p}}\right)
\end{array}\right)
$$

The exact solution of Equation (14) is written as

$$
\bar{T}(x, s)=\frac{f_{2}}{f_{1}}+A_{1} e^{\sqrt{f_{1}} x}+A_{2} e^{-\sqrt{f_{1}} x}+\frac{f_{3}}{f_{1}-k_{1}^{2}} e^{-k_{1} x}+\frac{f_{4}}{f_{1}-k_{1}^{2}} e^{-k_{2} x}
$$

To obtain the complete solution of (14), boundary conditions represented by Equation (11) are used to get the constants $A_{1}$ and $A_{2}$, which are written as

$$
\begin{gathered}
A_{1}=\frac{e^{-L\left(k_{1}+k_{2}\right)}\left(e^{L k_{2}}\left(e^{L k_{1}}-e^{L} \sqrt{\beta_{1}}\right) k_{1}\left(k_{2}^{2}-\beta_{1}\right) \beta_{3}+e^{L k_{1}}\left(e^{L k_{2}}-e^{L \sqrt{\beta_{1}}}\right) k_{1}^{2} k_{2} \beta_{4}-e^{L k_{1}}\left(e^{L k_{2}}-e^{L \sqrt{\beta_{1}}}\right) k_{2} \beta_{1} \beta_{4}\right)}{\left(e^{2 L \sqrt{\beta_{1}}}-1\right) \sqrt{\beta_{1}}\left(\beta_{1}-k_{1}^{2}\right)\left(\beta_{1}-k_{2}^{2}\right)} \\
A_{2}=\frac{e^{L} \sqrt{\beta_{1}}}{\left(e^{2 L} \sqrt{\beta_{1}}-1\right) \sqrt{\beta_{1}}}\left(\frac{e^{-L k_{1}}\left(e^{L\left(k_{1}+\sqrt{\beta_{1}}\right)}-1\right) k_{1} \beta_{3}}{k_{1}^{2}-\beta_{1}}+\frac{e^{-L k_{2}}\left(e^{L\left(k_{2}+\sqrt{\beta_{1}}\right)}-1\right) k_{2} \beta_{4}}{k_{2}^{2}-\beta_{1}}\right) .
\end{gathered}
$$

Finally, for the solutions of the temperature increment, a numerically reversal approach was adopted depending on Stehfest [27]. In this approach, the inverse $\mathrm{M}(x, t)$ of the Laplace transforms $\overline{\mathrm{M}}(x, s)$ can be approximated as

$$
M(x, t)=\frac{\ln 2}{t} \sum_{j=1}^{M} V_{j} \bar{M}\left(x, j \frac{\ln 2}{t}\right),
$$

where $V_{j}$ is given by the following equation:

$$
V_{j}=(-1)^{\frac{n}{2}+1} \sum_{k=\frac{i+1}{2}}^{\min \left(i, \frac{n}{2}\right)} \frac{k^{\frac{n}{2}+1}(2 k) !}{\left(\frac{n}{2}-k\right) ! k !(i-k) !(2 k-1) !}
$$

The evaluations of burns are one of the most remarkable attributes in the bio-engineering science in a living tissue. To quantify thermal damage, the technique expanded by Henriques and Moritz [28,29] can be used.

$$
\Omega=\int_{0}^{t} B e^{-\frac{E_{a}}{R T}} d t
$$

where $\mathrm{R}=8.313 \mathrm{~J} / \mathrm{mol} \cdot \mathrm{K}$ is the universal gas constant, $\mathrm{B}=3.1 \times 10^{98} \mathrm{~s}^{-1}$ is the factor of frequency, and $E_{a}=6.28 \times 10^{5} \mathrm{~J} / \mathrm{mol}$ is the activation energy.

\section{Results and Discussions}

Several simulations were conducted to test the performance of the proposed linear thermal model based on the bio-heat transfer model. For numerical computations, the values of thermal properties for living tissue were written [30].

$$
\rho_{b}=1060(\mathrm{~kg})\left(\mathrm{m}^{-3}\right), c_{b}=3860(\mathrm{~J})\left(\mathrm{kg}^{-1}\right)\left(k^{-1}\right), \omega_{b}=1.87 \times 10^{-3}\left(\mathrm{~s}^{-1}\right), \mathrm{T}_{b}=37^{\circ} \mathrm{C},
$$




$$
\begin{gathered}
c=4187(\mathrm{~J})\left(\mathrm{kg}^{-1}\right)\left(\mathrm{k}^{-1}\right), \rho=1000(\mathrm{~kg})\left(\mathrm{m}^{-3}\right), k=0.628(\mathrm{~W})\left(\mathrm{m}^{-1}\right)\left(\mathrm{k}^{-1}\right), \tau_{o}=5(\mathrm{~s}), \\
\tau_{p}=10(\mathrm{~s}), Q_{m}=1.19 \times 10^{3}(\mathrm{~W})\left(\mathrm{m}^{-3}\right), L=0.03(\mathrm{~m}), I_{o}=122 \times 10^{3}(\mathrm{~W})\left(\mathrm{m}^{-2}\right), g=0.9, \\
\mu_{s}=12000\left(\mathrm{~m}^{-1}\right), \mu_{a}=40\left(\mathrm{~m}^{-1}\right), T_{o}=37^{\circ} \mathrm{C} .
\end{gathered}
$$

Using MATLAB (R2017a) software, the computations are done and the results are presented graphically. The outer thermal source impact on the surface of the skin was integrated. These mathematical models, which are based on hyperbolic bio-heat transfer, were found with the interface and appropriate boundary conditions. The perfusions, metabolic, and conducting heat source terms were utilized in the formulations. A slab of tissue is $3 \mathrm{~cm}$ thick and the reference temperature is equal to its normal temperature, that is, $T_{b}=T_{o}=37^{\circ} \mathrm{C}$. In order to study the effect of fractional parameter $\alpha$, the laser exposure time $\tau_{p}$ and the thermal relaxation time $\tau_{o}$ on the temperature and the thermal damages, the numerical results were presented using the graphs as in Figures 1-9. Figure 1 displays the temperature variation along the distance $x$ at $t=80 \mathrm{~s}$ when the laser exposure and thermal relaxation times remine to constants $\tau_{p}=10 s, \tau_{o}=5 \mathrm{~s}$. It is observed that the temperature begins from the utmost values, and then decreases constantly to $T_{b}=37^{\circ} \mathrm{C}$. The time history of surface temperature through four values of the fractional order parameter $\alpha$ is exhibited in Figure 2. It notices that the temperature begins from $T_{b}$ and increases with the time till most values, after which decreases again to $T_{b}$. Figure 3 show the resulting thermal damage through time $t$. Clearly, the time history of the thermal damages obtained from the different values of the fractional order parameter $\alpha$ is very different. As expect, the fractional order parameter $\alpha$ has major effects on the distributions of the variables. Figures 4-6 display the influences of the laser exposure time $\tau_{p}$ with the fractional bioheat model $(\alpha=0.5)$ on the resulting thermal damage and the temperature distributions. As expected, the laser exposure time $\tau_{p}$ has a great effect on the resulting thermal damages and the distribution of temperature. As expected, the increase of laser exposure times increases the temperature, exceptionally at the peak temperature where the difference between the diagrams. On the basis of the fractional order bioheat model $(\alpha=0.5)$, the comparison of temperature response among four types of thermal relaxation time $\tau_{0}$ along $\mathrm{x}$ is shown in Figure 7. In these cases, it was observed that the thermal relaxation time decreases the temperature of the skin surface. Gradually, the temperature decreases continuously to the normal temperature. The time history of surface temperature through four values of the thermal relaxation time is shown in Figure 8. Moreover, Figure 9 displays the variations of thermal damages with time for various values of thermal relaxation time $\tau_{0}$. Figures 3,6 and 9 show the variations of thermal damage at the point $x=0$ under various values of the fractional parameter, the laser exposure time, and the thermal relaxation time, respectively. As observed in the figures, the thermal damages are reduced with the fractional model and hyperbolic bioheat model.

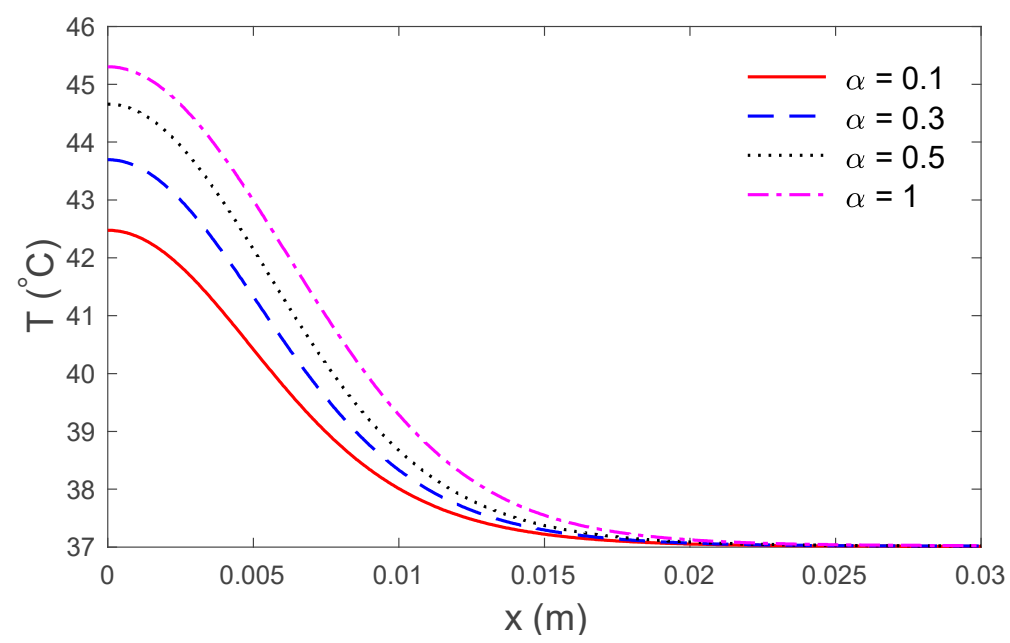

Figure 1. Temperature profile in skin tissue with and without fractional derivative. 


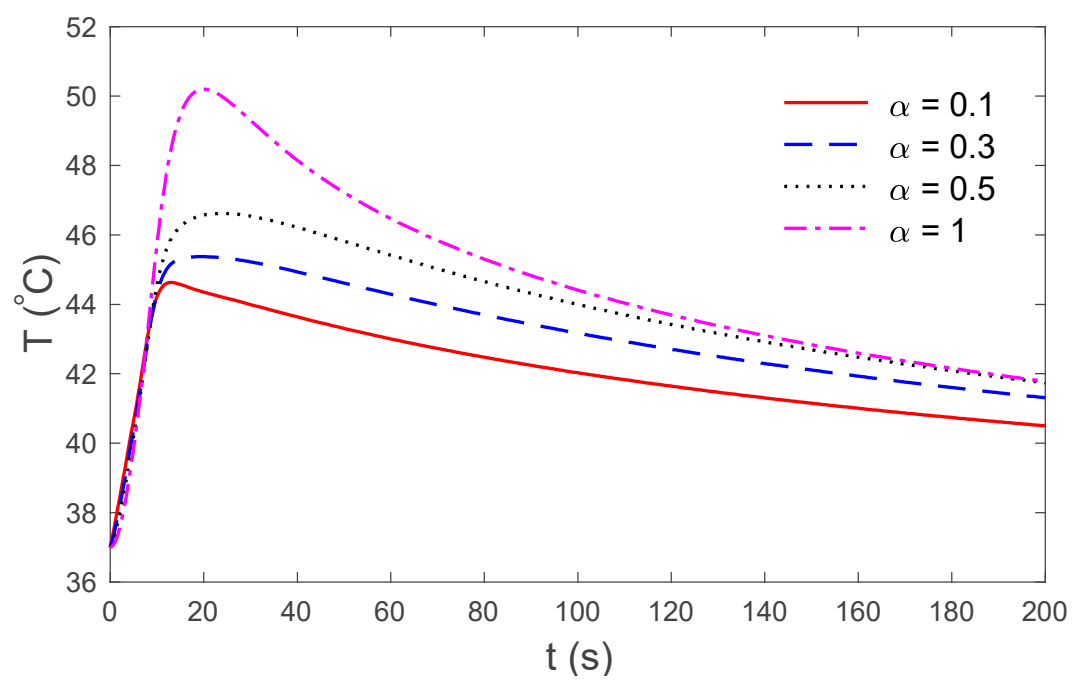

Figure 2. Temperature history at skin surface with and without fractional derivative.

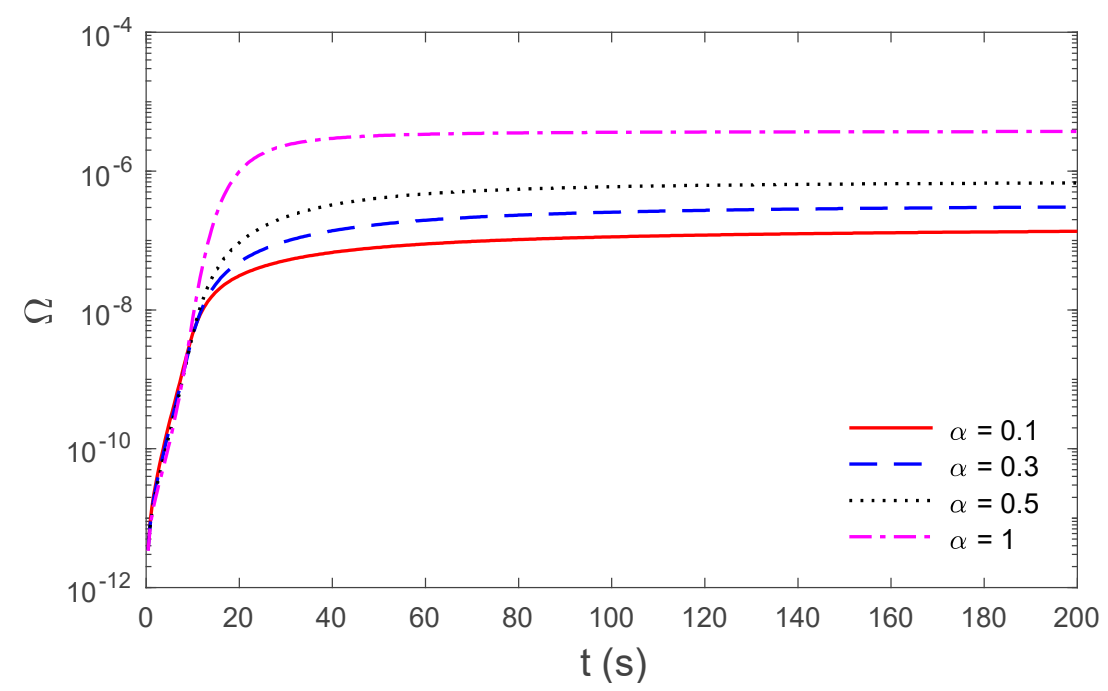

Figure 3. The variation of thermal damage at skin surface with and without fractional derivative.

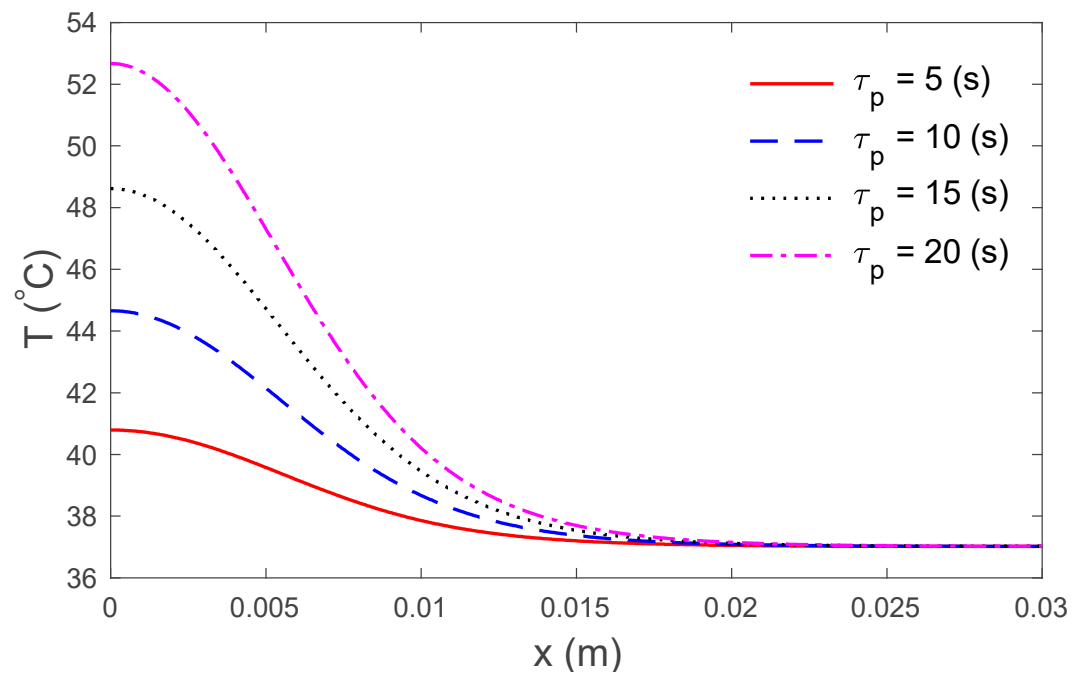

Figure 4. Temperature profile in skin tissue for different values of the laser exposure time $\tau_{p}$. 


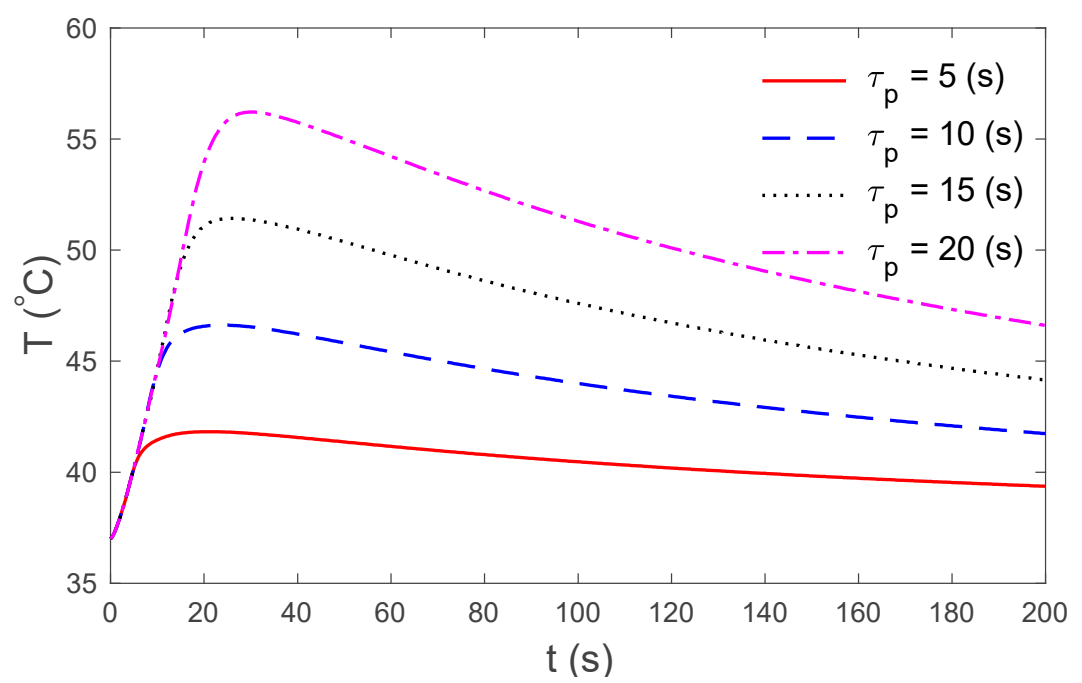

Figure 5. Temperature history at skin surface for different values of the laser exposure time $\tau_{p}$.

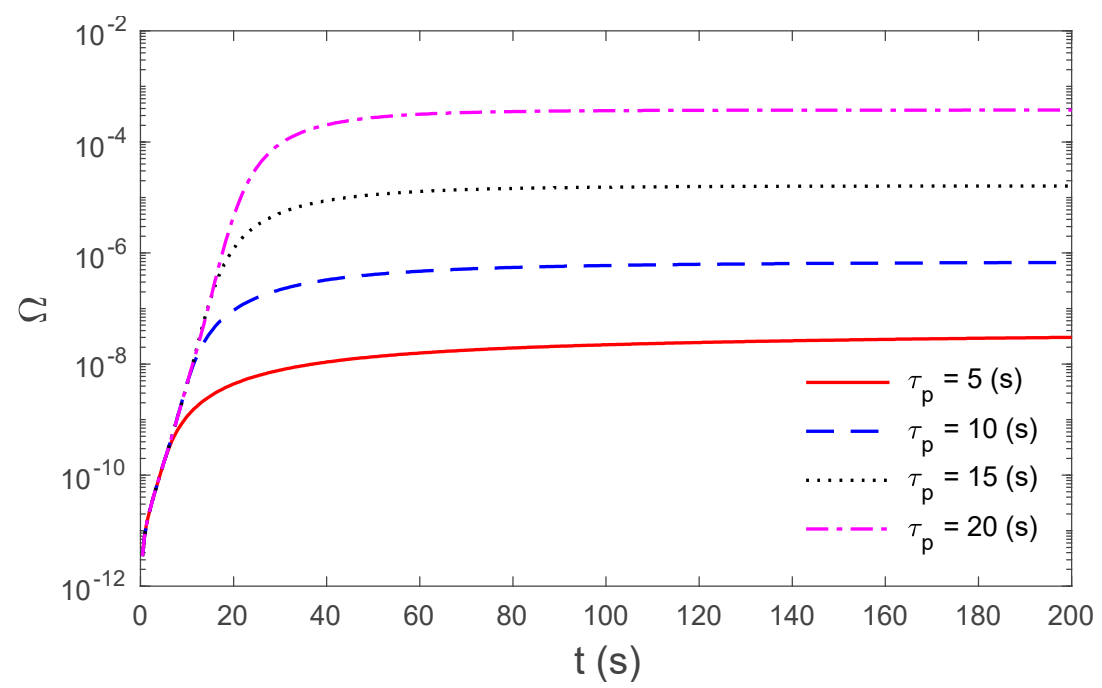

Figure 6. The variation of thermal damage with time for different values of the laser exposure time $\tau_{p}$.

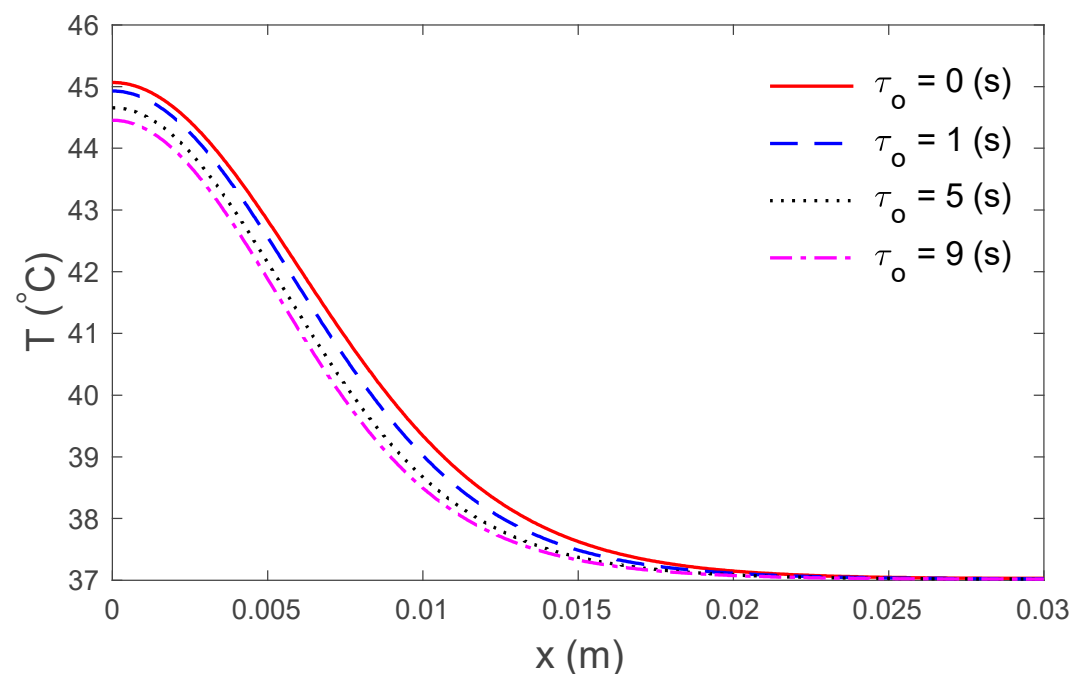

Figure 7. Temperature profile in skin tissue for different values of thermal relaxation time $\tau_{o}$. 


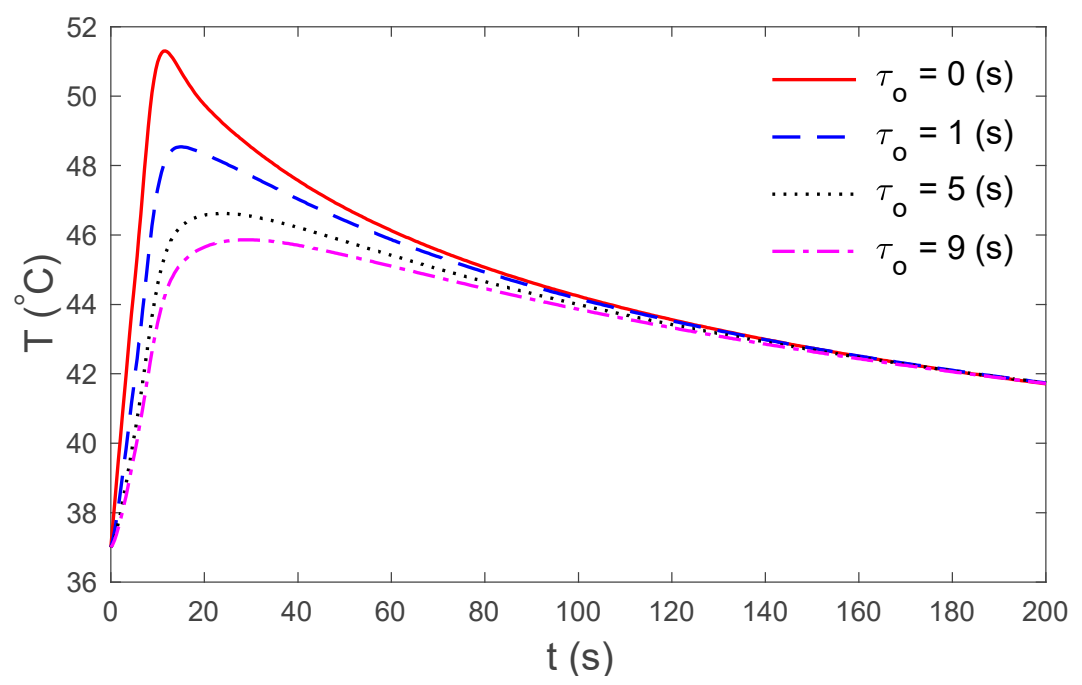

Figure 8. Temperature history at skin surface for different values of thermal relaxation time $\tau_{0}$.

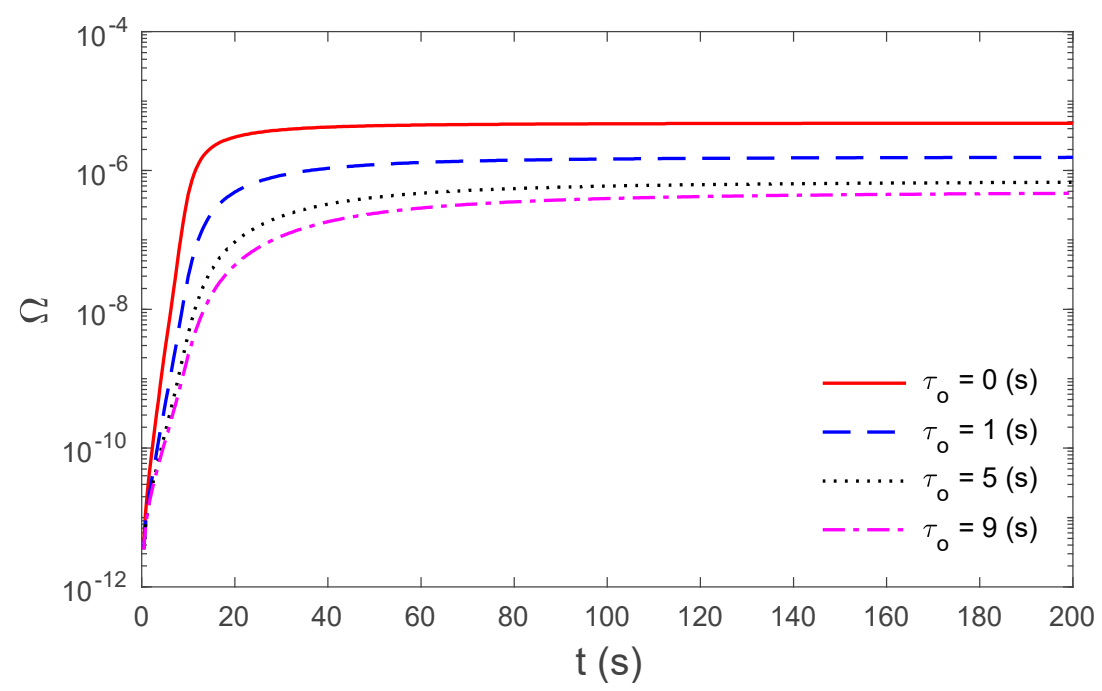

Figure 9. The variation of thermal damage with time for different values of thermal relaxation time $\tau_{0}$.

\section{Conclusions}

On the basis of the fractional order bio-heat model in a living tissue, the generalized bio-heat equation was proposed, through the substitution of the rate of change term by a fractional time derivative. The fractional-order bio-heat transfer model is derived and its effect is given in thermotherapy application. The thermal damages are reduced with the fractional model and hyperbolic bioheat model. We believe that the analysis of the present study will be useful to understand the basic features of this new model for bioheat conduction.

Author Contributions: All four authors conceived the framework and structured the whole manuscript, checked the results, and completed the revision of the paper. The authors have equally contributed to the elaboration of this manuscript. All authors have read and approved the final form of the manuscript.

Funding: This research received no external funding.

Acknowledgments: This project was funded by the Deanship of Scientific Research (DSR) at King Abdulaziz University, Jeddah, Saudi Arabia, under grant no. (KEP-72-130-38). The authors, therefore, acknowledge with thanks DSR technical and financial support.

Conflicts of Interest: The authors declare no conflicts of interest. 


\section{References}

1. Mahjoob, S.; Vafai, K. Analytical characterization of heat transport through biological media incorporating hyperthermia treatment. Int. J. Heat Mass Transf. 2009, 52, 1608-1618. [CrossRef]

2. Gabay, I.; Abergel, A.; Vasilyev, T.; Rabi, Y.; Fliss, D.M.; Katzir, A. Temperature-controlled two-wavelength laser soldering of tissues. Lasers Surg. Med. 2011, 43, 907-913. [CrossRef] [PubMed]

3. Zhou, J.; Chen, J.; Zhang, Y. Dual-phase lag effects on thermal damage to biological tissues caused by laser irradiation. Comput. Biol. Med. 2009, 39, 286-293. [CrossRef] [PubMed]

4. Pennes, H.H. Analysis of tissue and arterial blood temperatures in the resting human forearm. J. Appl. Physiol. 1948, 1, 93-122. [CrossRef] [PubMed]

5. Cattaneo, C. A form of heat conduction equation which eliminates the paradox of instantaneous propagation. Compt. Rendu 1958, 247, 431-433.

6. Vernotte, P. Les paradoxes de la theorie continue de l'equation de la chaleur. Compt. Rendu 1958, 246, 3154-3155.

7. Hobiny, A.D.; Abbas, I.A. Theoretical analysis of thermal damages in skin tissue induced by intense moving heat source. Int. J. Heat Mass Transf. 2018, 124, 1011-1014. [CrossRef]

8. Gupta, P.K.; Singh, J.; Rai, K. Numerical simulation for heat transfer in tissues during thermal therapy. J. Therm. Biol. 2010, 35, 295-301. [CrossRef]

9. Gupta, P.K.; Singh, J.; Rai, K.; Rai, S. Solution of the heat transfer problem in tissues during hyperthermia by finite difference-decomposition method. Appl. Math. Comput. 2013, 219, 6882-6892. [CrossRef]

10. Dillenseger, J.-L.; Esneault, S. Fast FFT-based bioheat transfer equation computation. Comput. Biol. Med. 2010, 40, 119-123. [CrossRef]

11. Zhu, D.; Luo, Q.; Zhu, G.; Liu, W. Kinetic thermal response and damage in laser coagulation of tissue. Lasers Surg. Med. 2002, 31, 313-321. [CrossRef] [PubMed]

12. Ezzat, M.A.; AlSowayan, N.S.; Al-Muhiameed, Z.I.; Ezzat, S.M. Fractional modelling of Pennes' bioheat transfer equation. Heat Mass Transf. 2014, 50, 907-914. [CrossRef]

13. Ezzat, M.A.; El-bary, A.A.; Al-sowayan, N.S. Tissue responses to fractional transient heating with sinusoidal heat flux condition on skin surface. Anim. Sci. J. 2016, 87, 1304-1311. [CrossRef] [PubMed]

14. Ghanmi, A.; Abbas, I.A. An analytical study on the fractional transient heating within the skin tissue during the thermal therapy. J. Therm. Biol. 2019, 82, 229-233. [CrossRef]

15. Mondal, S.; Sur, A.; Kanoria, M. Transient heating within skin tissue due to time-dependent thermal therapy in the context of memory dependent heat transport law. Mech. Based Des. Struct. Mach. 2019, 1-15. [CrossRef]

16. Díaz, S.H.; Nelson, J.S.; Wong, B.J. Rate process analysis of thermal damage in cartilage. Phys. Med. Biol. 2002, 48, 19. [CrossRef]

17. Abbas, I.A.; Zenkour, A.M. The effect of rotation and initial stress on thermal shock problem for a fiber-reinforced anisotropic half-space using Green-Naghdi theory. J. Comput. Theor. Nanosci. 2014, 11, 331-338. [CrossRef]

18. Abbas, I.A.; El-Amin, M.; Salama, A. Effect of thermal dispersion on free convection in a fluid saturated porous medium. Int. J. Heat Fluid Flow 2009, 30, 229-236. [CrossRef]

19. Abbas, I.A. The effects of relaxation times and a moving heat source on a two-temperature generalized thermoelastic thin slim strip. Can. J. Phys. 2015, 93, 585-590. [CrossRef]

20. El-Naggar, A.; Kishka, Z.; Abd-Alla, A.M.; Abbas, I.A.; Abo-Dahab, S.M.; Elsagheer, M. On the initial stress, magnetic field, voids and rotation effects on plane waves in generalized thermoelasticity. J. Comput. Theor. Nanosci. 2013, 10, 1408-1417. [CrossRef]

21. Marin, M. Cesaro means in thermoelasticity of dipolar bodies. Acta Mech. 1997, 122, 155-168. [CrossRef]

22. Marin, M.; Ellahi, R.; Chirilă, A. On solutions of Saint-Venant's problem for elastic dipolar bodies with voids. Carpathian J. Math. 2017, 33, 219-232.

23. Marin, M.; Nicaise, S. Existence and stability results for thermoelastic dipolar bodies with double porosity. Contin. Mech. Thermodyn. 2016, 28, 1645-1657. [CrossRef]

24. Abbas, I.A. Nonlinear transient thermal stress analysis of thick-walled FGM cylinder with temperature-dependent material properties. Meccanica 2014, 49, 1697-1708. [CrossRef]

25. Zenkour, A.M.; Abbas, I.A. Magneto-thermoelastic response of an infinite functionally graded cylinder using the finite element method. J. Vib. Control. 2014, 20, 1907-1919. [CrossRef] 
26. Gardner, C.M.; Jacques, S.L.; Welch, A. Light transport in tissue: Accurate expressions for one-dimensional fluence rate and escape function based upon Monte Carlo simulation. Lasers Surg. Med. 1996, 18, 129-138. [CrossRef]

27. Stehfest, H. Algorithm 368: Numerical inversion of Laplace transforms [D5]. Commun. ACM 1970, 13, 47-49. [CrossRef]

28. Henriques, F., Jr.; Moritz, A.R. Studies of thermal injury: I. The conduction of heat to and through skin and the temperatures attained therein. A theoretical and an experimental investigation. Am. J. Pathol. 1947, 23, 530.

29. Moritz, A.R.; Henriques, F., Jr. Studies of thermal injury: II. The relative importance of time and surface temperature in the causation of cutaneous burns. Am. J. Pathol. 1947, $23,695$.

30. Askarizadeh, H.; Ahmadikia, H. Analytical analysis of the dual-phase-lag model of bioheat transfer equation during transient heating of skin tissue. Heat Mass Transf. 2014, 50, 1673-1684. [CrossRef]

C 2020 by the authors. Licensee MDPI, Basel, Switzerland. This article is an open access article distributed under the terms and conditions of the Creative Commons Attribution (CC BY) license (http://creativecommons.org/licenses/by/4.0/). 